\title{
O processo de diagnóstico e de intervenção do psicólogo do trabalho
}

\author{
Beatriz Marcondes de Azevedo ${ }^{1}$ e Roberto Moraes Cruz ${ }^{2}$ \\ Universidade Federal de Santa Catarina
}

\begin{abstract}
A atuação do psicólogo do trabalho envolve estudos em relação aos determinantes e às conseqüências que o sistema de produção gera para a saúde do trabalhador. Porém, muitas vezes, tais estudos têm enfocado apenas os fatores de trabalho restritivos ou negativos que repercutem de forma nefasta no meio organizacional. $O$ diagnóstico e a intervenção do psicólogo têm sido assim pautados em abordagens mais curativas que preventivas, com um olhar focado apenas no entendimento e no controle das conseqüências das condutas dos trabalhadores, expressas nas queixas dos gestores, referentes aos problemas com a produtividade, acidentes de trabalho, doenças ocupacionais etc. A compreensão das situações nas quais se estruturam tais conseqüências não tem recebido a devida importância. Para que a atuação do psicólogo do trabalho não seja reducionista e tenha resultado eficaz, a lógica de seu pensamento não deve apenas centrar-se nas conseqüências das condutas humanas, mas principalmente na identificação das variáveis críticas relacionadas às exigências das tarefas, aos riscos potenciais e adicionais do trabalho, às cargas de trabalho e ao desempenho humano. Sistematizar conhecimento a respeito dos aspectos presentes no processo de diagnóstico e propiciar uma reflexão crítica sobre o exercício do psicólogo do trabalho são os objetivos centrais do presente artigo.
\end{abstract}

Palavras-chave: Análise do trabalho, Processo de diagnóstico e intervenção, Atuação do psicólogo do trabalho.

The work psychologist's diagnosis and intervention process

The work psychologist field involves studies about the causes and the consequences that production systems generate for worker's health. However, these studies often have focused only on restrictive or negative work factors, producing nefarious consequences on the organizational environment. Thus, the psychologist diagnosis and intervention have been based on corrective's approaches rather than preventive ones, focusing only the understanding and the control of the consequences of workers' conduct, expressed through managers who concern about productivity's, work accidents', occupational illness' problems, etc. The understanding of the situations which structure these consequences, do not have been received the appropriate attention. In other that the psychologist action were not reducionist and have effective results, the logical of his thinking must not focus on the human conducts' consequences, but mainly on the identification of critical variables related to task's requirements, to the potential and additional work risks, to the great quantity of work and to the human performance. Systematize knowledge about the issues involved in the diagnosis process and give a critical reflection about the work psychologist activities, which are the main aims of this paper.

Keywords: Work analysis, Diagnosis and intervention process, Work psychologist field.

\section{Introdução}

A imagem da psicologia do trabalho brasileira ainda é, muitas vezes, associada ao modelo clínico curativista, pois aos psicólogos, assim como aos médicos, solicita-se a elaboração de um diagnóstico a partir de sintomas específicos e espera-se a prescrição de soluções rápidas e de certa forma padronizadas. Apenas algumas partes do todo que está sendo investigado são levadas em consideração durante o processo de análise e compreensão da situação em questão, tendendo-se por isso a uma atuação reducionista e muitas vezes pouco eficiente.

\footnotetext{
1 Doutoranda em engenharia de produção pela UFSC, psicóloga e administradora pela UFSC, docente do curso de psicologia da Universidade do Planalto Catarinense e do curso de administração da Faculdade de Capivari. E-mail: biabizzy@ig.com.br
}

2 Doutor em engenharia de produção pela UFSC, psicólogo e engenheiro civil pela UFBA, docente do curso de graduação e pósgraduação em psicologia da UFSC e do curso de pós-graduação em engenharia da produção da UFSC. E-mail: rcruz@cfh.ufsc.br 
Nessa concepção, no âmbito das organizações, os psicólogos são chamados para intervir no momento do surgimento de sintomas. Tais sintomas são entendidos como conseqüências negativas resultantes do processo de trabalho e são comumente expressos em queixas das mais diversas ordens como, por exemplo, problemas referentes à queda na produtividade, relacionados à qualidade dos produtos, crescentes índices de absenteísmo e rotatividade, desencadeamento de doenças, aumento da freqüência ou da gravidade de acidentes de trabalho, desmotivação, insatisfação, descomprometimento etc.

Com base na queixa, procura-se uma lógica de causalidade linear e o diagnóstico e a intervenção são organizados desse modo a partir da noção de nexo causal. A não consideração da multideterminação dos sintomas impede que se compreenda profundamente o sistema que ocasionou essas conseqüência e tende a levar a uma intervenção superficial.

As evidências demonstram que uma contribuição mais consistente por parte do psicólogo requer uma preocupação prevencionista e que ressalte no processo de análise da situação de trabalho os principais fatores organizacionais que potencializam a produtividade do sistema e a saúde dos trabalhadores. A viabilização de intervenções profiláticas depende da capacidade do psicólogo de conseguir "superar as relações de determinação entre os fenômenos psicológicos (nexo causal) pelas relações entre as variáveis ou fenômenos presentes na situação-problema a ser investigada ou avaliada" (Cruz, 2002, p. 22).

Nesse sentido, no momento em que houver demanda para que o psicólogo disponibilize seu saber a serviço da organização, alguns aspectos referentes à maneira de investigação necessitam ser investigados, assegurando, assim, o alcance de resultados eficientes. Tais aspectos dizem respeito à composição e à decomposição dos indicadores de produção, desempenho e saúde, tanto positivos, como negativos, uma vez que devido à complexidade da inter-relação entre o trabalho e o processo de saúde-doença, há de se descobrir quais são as principais variáveis que, relacionadas em um certo grau, freqüência e intensidade contribuem para a prevalência de bem-estar ou mal-estar no trabalho.

O objetivo deste artigo, portanto, é destacar os principais aspectos que devem ser considerados ao longo do processo de diagnóstico e de intervenção do psicólogo nas organizações. Em outras palavras, espera-se, com base numa revisão de literatura, poder sistematizar conhecimentos que permitam fazer uma reflexão crítica acerca do fazer do psicólogo do trabalho, apontando as principais características e necessidades presentes ao longo do processo de abordagem num determinado sistema de trabalho.

\section{O estudo da psicologia do trabalho}

A psicologia do trabalho, segundo Cruz (2005), é uma disciplina que busca descrever e explicar fenômenos e processos psicológicos na atividade de trabalho a partir das condições estabelecidas pelo meio técnico e social. Também é uma área de especialização dentro da ciência psicológica que tem como objeto central a categoria trabalho.

Assim, para a psicologia não é possível pensar o trabalho deslocado da ação humana, justamente porque seu objeto de estudo está relacionado com fenômenos ou processos psicológicos presentes na atividade de trabalho.

Para estudar o trabalho torna-se necessário fazer delimitações e situá-lo no contexto em que ocorre. Uma vez contingenciado, quatro características - exigência, risco, carga e desempenho humano - devem ser exploradas, independente da natureza da atividade que esteja sendo enfocada. 
A Figura 1 ilustra o circuito do trabalho, destacando as variáveis inerentes em qualquer atividade e assinalando que as decorrências, ou seja, as conseqüências que ocorrem em função de determinadas exigências, trazem implícita a noção de desempenho humano, pois é essa relação funcional que vai permitir a expressão das competências individuais.

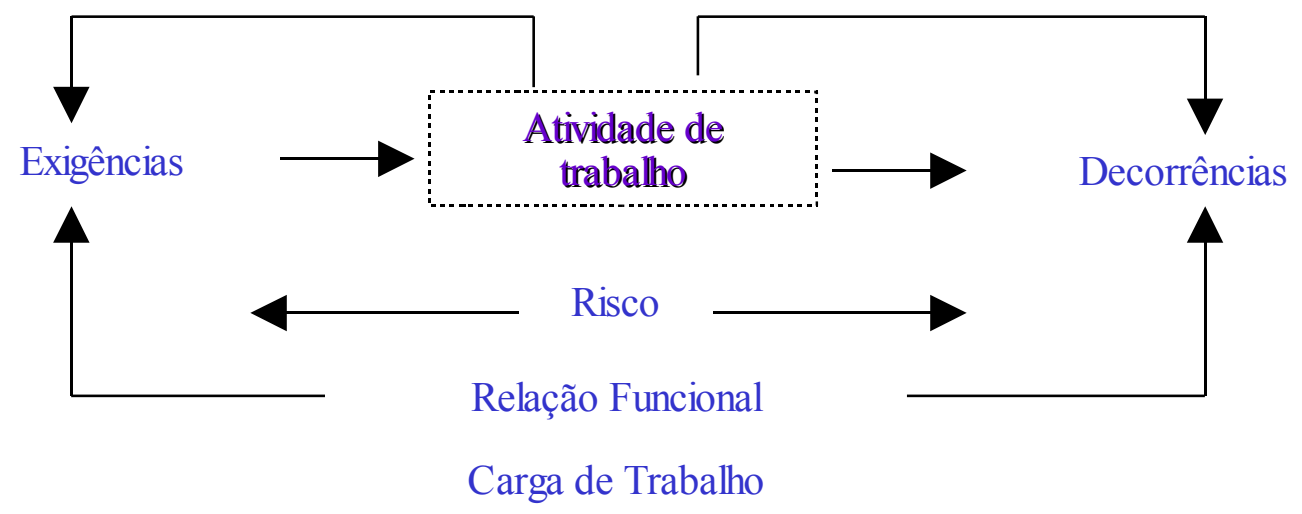

Figura 1: Circuito do Trabalho (Fonte: Cruz, 2005).

O processo de investigação da atividade de trabalho requer a obtenção do conhecimento sobre as características do trabalhador, as condições de execução do trabalho, as conseqüências geradas na relação com a atividade e sobre a atuação do operador do ponto de vista das suas competências e habilidades.

$\mathrm{Na}$ execução de qualquer atividade estão presentes variáveis que se relacionam em diferentes níveis e graus e que, organizadas de forma singular, geram conseqüências que são expressas a partir variações dos indicadores de produção, de desempenho humano e de saúde do sistema organizacional ou do próprio trabalhador em questão.

Em síntese, diz-se que a análise de uma determinada atividade de trabalho requer do psicólogo o estudo do sistema comportamental dentro das condições estabelecidas pelo meio técnico e social.

Nesse sentido, cabe ao psicólogo evitar uma abordagem reducionista que leve em conta apenas o posto de trabalho ou as conseqüências geradas ao longo do circuito do trabalho. A análise é complexa, pois o sistema de trabalho é composto por um conjunto de variáveis, que pela impossibilidade de mapear todas elas, faz-se um recorte da situação buscando identificar as mais críticas e descobrir como elas estão relacionadas entre si. De acordo com Cruz (2004, p. 12):

O mais importante é reconhecer que a situação de trabalho produz inúmeros eventos comportamentais direta e indiretamente associados entre si, dos quais importa compreender seus nexos, as particularidades que os envolvem e porque são tão significativos e determinantes para o bem estar ou o adoecimento físico e psicológico.

É através da análise das exigências da atividade que se possibilita ao psicólogo elencar o conjunto de variáveis que influenciam o desencadeamento de conseqüências; conseqüências essas expressas nos indicadores de produção, desempenho e saúde. 


\section{Características a serem exploradas na análise do trabalho}

Ao partir do pressuposto de que toda atividade tem exigências e decorrências, a primeira variável a ser levada em consideração no processo de diagnóstico de uma determinada situação de trabalho é a noção de exigência.

\section{Noção de exigência}

A forma como o trabalho está organizado e o contexto em que está inserido determinam as exigências das atividades realizadas pelos trabalhadores visando o alcance dos objetivos organizacionais. Entretanto, os meios técnicos disponíveis e as idiossincrasias dos indivíduos estarão constantemente influenciando o grau das exigências, contribuindo também para a ocorrência de outras exigências formuladas a qualquer momento da execução das atividades.

Assunção (2003) refere-se as essas exigências como sendo os fatores intervenientes na produção e que podem incorrer em incidentes e variações, mudando, assim, a situação de trabalho. O autor exemplifica tais intervenientes como o caso da matéria-prima que não foi fornecida a tempo ou na qualidade desejada, os desgastes das ferramentas, a desregulação ou quebra das máquinas, as faltas de colegas ou a entrada de novatos na empresa, as modificações dos modelos dos produtos etc.

Para Leplat e Cuny (1977), o psicólogo, ao conhecer detalhadamente a situação de trabalho, obtém subsídios para elaborar descrições dos seus diferentes componentes tanto em termos materiais, como organizacionais, ambientais e humanos relacionados à atividade que está sendo analisada.

Os mesmos autores sugerem que a investigação das exigências ocorra a partir da identificação de aspectos referentes às categorias: esquemas de processo, esquemas da organização homem-máquina e esquemas do funcionamento homem-máquina. Nessas três categorias poderão estar presentes:

a) Exigências físicas: relacionadas à tarefa e à situação (esforços dinâmicos e estáticos); relacionadas com o organismo humano (posturas, movimentos, dispêndio de energia, reações cardiovasculares, reações respiratórias e térmicas);

b) Exigências ambientais (iluminação, temperatura, ambiência sonora);

c) Exigências sensoriais (relativas às fontes de informações e aos órgãos sensoriais);

d) Exigências sensoriomotoras (relativas aos dispositivos sinais-comandos e as características antropométricas do trabalhador);

e) Exigências mentais (avaliações relativas às características da tarefa e relacionadas com o operador).

De uma maneira mais simples e resumida, diz-se que a partir de informações referentes às características da organização (setor de atuação, porte, estrutura, situação financeira, a imagem organizacional, políticas e diretrizes etc.), às características dos produtos e processos produtivos (quantidades a serem produzidas, aos prazos a serem cumpridos, às regras e às normas a serem seguidas, às máquinas e aos equipamentos a serem operadas etc.) e características dos trabalhadores (idade, sexo, estrutura física, estado civil, experiência, conhecimento, competências etc.) é que se torna possível mapear as exigências requeridas em seus diversos níveis e graus ao longo do processo produtivo. 


\section{Noção de risco}

A probabilidade de ocorrer um dano (riscos potenciais e adicionais) está presente em qualquer situação de trabalho, em diferentes graus e níveis, dependendo do tipo de organização e da natureza da atividade realizada.

Segundo a NR 9 (Manuais de Legislação Atlas, 2003), os riscos inerentes ao âmbito do trabalho são denominados de riscos ambientais e decompostos em agentes físicos, químicos e biológicos e que, devido sua natureza, concentração ou intensidade e tempo de exposição, são capazes de causar danos à saúde do trabalhador.

Consideram-se agentes físicos diversas formas de energia a que possam estar expostos os trabalhadores, tais como ruído, vibrações, pressões anormais, temperaturas extremas, radiações ionizantes, radiações não ionizantes, bem como o infra-som e o ultra-som. Agentes químicos são as substâncias, compostos ou produtos que possam penetrar no organismo pelas vias respiratórias na forma de poeiras, fumos, névoas, neblinas, gases ou vapores, ou que, pela natureza da atividade de exposição, possam ter contato ou ser absorvidos pelo organismo através da pele ou por ingestão. Os agentes biológicos são as bactérias, fungos, bacilos, parasitas, protozoários, vírus, dentre outros.

A NR 17, que discorre sobre a ergonomia, menciona nos artigos 17.6.1 e 17.6.2 que a organização do trabalho (normas de produção, modo operatório, exigência de tempo, determinação do conteúdo de tempo, ritmo de trabalho e conteúdo das tarefas) deve ser adequada às características psicofisiológicas dos trabalhadores e à natureza do trabalho.

\section{Noção de carga de trabalho}

A noção de carga de trabalho está intrinsecamente relacionada com o conceito de trabalho prescrito (tarefa) e trabalho real (atividade), pois a passagem do que foi prescrito pela organização do trabalho para sua realização propriamente dita implica em um maior ou menor custo humano do trabalho. Nessa ótica, Ferreira e Freire (2001) classificam as duas dimensões do trabalho (o prescrito e o real) como vetores da carga de trabalho.

Leplat e Cuny (1977) assinalam que, num primeiro momento, pensava-se que a carga de trabalho estava diretamente ligada a resposta a uma determinada exigência da atividade e, por isso, ela acabou algumas vezes sendo confundida com o conceito de risco. Wisner (1987) contribuiu para ampliar o entendimento do conceito de carga de trabalho, defendendo a idéia de que para o trabalhador responder às exigências da atividade era necessário também controlar os efeitos de sua ação.

Ferreira e Freire (2001) afirmam que não existe um consenso em relação ao conceito de carga, pois ele aparece marcado por controvérsias, ambigüidade e imprecisão. Entretanto, segundo eles, na maior parte dos trabalhos científicos a noção de carga encontra-se associada a dois aspectos. Primeiro, às variáveis presentes na situação de trabalho que agem de forma combinada e geram impacto no trabalhador, exigindo dele um esforço contínuo de regulação e adaptação. Segundo, à função mediadora da carga para compreender a inter-relação trabalho-desgaste vivenciada pelos trabalhadores.

Articulando esses dois entendimentos, tem-se então a noção de carga expressa através da inter-relação funcional entre as exigências presentes na situação de trabalho e as conseqüências geradas pelas estratégias que os trabalhadores utilizam para garantir o alcance dos objetivos prescritos pela organização, bem como para o desenvolvimento da competência profissional que, quanto mais desenvolvida, melhores são suas possibilidades de preservação do seu bem-estar e de evitação de dissonâncias cognitivas. 
Segundo Wisner (1994), a carga de trabalho está didaticamente dividida em: física e mental (cognitiva e psíquica). A carga física pode ser facilmente percebida através de posturas, gestos e deslocamento. A carga mental já é mais difícil de ser avaliada, pois se refere à capacidade percepto-cognitiva do indivíduo, incluindo aí os processos de atenção, concentração, memorização, tomada de decisão e os afetos mobilizados para atender às exigências da atividade. Para esse autor, a carga de trabalho está presente, em maior ou menor grau, ao longo de todo o circuito do trabalho, mediando as exigências e as conseqüências para assegurar a evitação de reflexos desagradáveis para o próprio trabalhador e para o coletivo de trabalhadores envolvidos.

Em outros termos, as cargas dão indício de como o trabalho é tensionado. Assim, elas são inferidas e reconhecidas nas sobrecargas ou nas subcargas. Ambas situações ocorrem de maneira particular e única em cada trabalhador a partir do momento que surge um desequilíbrio entre as exigências da tarefa e a capacidade de resposta a elas. Tais desequilíbrios podem ser sinalizados mediante sintomas de desprazer, queda na produtividade, na qualidade, absenteísmo, rotatividade, licenças para tratamento de doenças, incidentes e acidentes de trabalho.

A expressão de desconforto na carga, por ser entendida como resultante do circuito de trabalho, é inferida a partir da seguinte analogia: quanto maior o desprazer percebido, maior é grau de risco do trabalho e maior do desequilíbrio da carga e sofrimento do trabalhador.

Dejours (1994) traz uma contribuição importante ao afirmar que uma das maneiras dos trabalhadores lidarem com as conseqüências das tensões desequilibrantes é a utilização de mecanismos de defesas individuais ou coletivos, expressos mediante condutas de negação, eufemização, burla, somatização, isolamento, esquiva etc. Tais estratégias de defesa são desenvolvidas como tentativas para controlar a carga de trabalho e enfrentar a sobrecarga.

\section{Noção de desempenho humano}

O desempenho humano é percebido mediante uma relação funcional entre as exigências e as conseqüências da situação de trabalho. As prescrições eliciam nos trabalhadores uma série de operações para responder às necessidades da organização do sistema produtivo. Tais operações são expressas em desempenhos e podem assumir conotações positivas ou negativas. Entretanto, cabe lembrar que as exigências são inerentes às condições de execução do trabalho e tal fato inexoravelmente implica na presença de riscos e da carga de trabalho.

\section{Análise da atividade a partir de seu propósito}

$\mathrm{Na}$ análise do trabalho o psicólogo considera também o objetivo da atividade e, a partir desse propósito, identifica as variáveis presentes nas seguintes categorias: indivíduo, condições de execução, conseqüências e competências e habilidades do trabalhador. 


\section{Variabilidade humana}

São diversos os aspectos que diferenciam os trabalhadores. As principais características que os tornam seres únicos dizem respeito às variáveis físicas, aos padrões emocionais, aos estilos cognitivos e aos níveis de representação do conhecimento e dos graus de qualificações.

Para Guérin, Laville, Daniellou, Duraffourg e Kerguelen (2001), a análise do trabalho permite compreender como os trabalhadores enfrentam as variações das situações. Tal enfrentamento é influenciado pela diversidade individual, em relação a estatura e gênero, e pela diversidade intra-individual, referente às alterações do estado de cada um quanto aos efeitos dos ritmos biológicos, fadiga ligada aos acontecimentos do dia, fadiga acumulada entre feriados e efeitos do envelhecimento.

As idiossincrasias dos trabalhadores necessitam ser cuidadosamente ponderadas na análise do trabalho. Ao atender uma demanda de intervenção feita a partir de uma solicitação dos responsáveis pela organização e expressa em queixas referentes às conseqüências negativas geradas na situação de trabalho, o psicólogo leva também em consideração que, segundo Wisner (1994, p. 19):

Todo indivíduo chega ao trabalho com seu capital genético, remontando o conjunto de sua história patológica antes do nascimento, à sua existência in útero, e com as marcas acumuladas das agressões físicas e mentais sofridas na vida. Ele traz também seu modo de vida, seus costumes pessoais e étnicos, seus aprendizados. Tudo isso pesa no custo pessoal da situação de trabalho.

Wisner (1994) assinala também que as condições de vida dos trabalhadores são variáveis de semelhante importância, pois diferentes formas de habitação, o tipo de transporte e a duração do trajeto, as cargas familiares, as atividades extralaborais vão contribuir para minimizar ou maximizar os efeitos nefastos do mundo do trabalho.

\section{Condições de execução do próprio trabalho}

As condições de execução do trabalho são entendidas como os meios de trabalho, ou seja, a maneira como ele deve ser executado a partir do meio físico onde se situa o posto de trabalho, do modo de utilização das ferramentas, máquinas e equipamentos, do tempo concedido para cada operação, das estratégias individuais, das regras e normas que devem ser respeitadas, a duração da jornada de trabalho, os turnos de trabalho, dos tipos de remuneração, das formas de controle e sanções e das relações interpessoais.

Em outras palavras, em relação às condições do trabalho, percebe-se a dimensão da tarefa prescrita em termos formais e informais quando Montmollin (1990) aborda essa questão referindo-se ao entendimento de tudo aquilo que está posto ao trabalhador e de tudo que se espera que ele faça. Nessa mesma ótica, Ferreira (2004) comenta sobre a existência de uma rede de crenças de ser e fazer presente no cotidiano das organizações. $\mathrm{O}$ ser refere-se aos objetivos e metas a serem atingidas; do respeito aos prazos pré-estabelecidos; dos procedimentos sociotécnicos a respeitar; das modalidades de utilização instrumental e dos critérios de quantidade e qualidade. $\mathrm{O}$ fazer está relacionado com as regras de relações socioprofissionais; modos de conduta organizacional; responsabilidades diversas; respeito à hierarquia de comando e disciplina para objetivos. 


\section{Conseqüências geradas na relação com a atividade}

As conseqüências geradas na relação com a atividade, como ilustradas na Figura 1 (referente ao circuito do trabalho), são exploradas a partir do estudo das cargas de trabalho, pois sua análise ocorre a partir das especificidades das exigências que a tarefa requer do trabalhador.

Os desequilíbrios entre exigências e conseqüências e as restrições do controle sobre seus efeitos refletem negativamente no sistema organizacional pela sobrecarga ou subcarga de trabalho expressas por sentimentos de desprazer e de frustrações, sintomas de doenças, aumento na freqüência ou na gravidade dos acidentes e dos índices de absenteísmo e rotatividade. Por outro lado, se a tensão entre as dimensões não se desequilibra, derivam-se dessa relação funcional processos de satisfação, sentimentos de prazer e de bem-estar no trabalho e aumento da produtividade.

Assim, para Cruz (2004, p. 236), "o estudo das cargas de trabalho serve como parâmetro de análise dos impactos de componentes do processo de trabalho sobre a saúde do trabalhador". Conhecer quais são e como se articulam as variáveis componentes das cargas é de grande valia para o diagnóstico e para a intervenção do psicólogo, pois é sabido que, em última instância, o processo de saúde tem repercussões imediatas no desempenho e na produção.

\section{Competência e habilidades}

A compreensão da competência do trabalhador está relacionada à sua capacidade de regulação, ou ainda, de gerir a variabilidade conforme as particularidades da situação. Para Vergnaud (1985, citado por Gomes, 1999), a competência de um indivíduo pressupõe um repertório de procedimentos e de métodos alternativos que lhe possibilita a adequação às diferentes situações que se apresentam.

Segundo Cruz (2005), para avaliar as competências e habilidades, em tese, deve-se avaliar como os indivíduos lidam com as conseqüências da situação de trabalho. A competência não é exatamente uma característica do trabalhador, mas sim a maneira pela qual o trabalhador demonstra seu grau de autonomia sobre as conseqüências geradas em função das exigências postas pela organização do trabalho. Entretanto, o mesmo autor assinala que o desenvolvimento de competências e de habilidades depende de uma "plataforma de aptidão". Em outros termos, a aptidão é a capacidade atualizada de poder agir em relação a uma determinada situação. As competências são um conjunto de aptidões com mais qualidade e, a habilidade, por sua vez, é a especialidade das competências.

De outra forma, Zafirian (1994, citado por Fleury, 2002) afirma que um trabalhador competente é aquele que é capaz de assumir iniciativas, ir além do prescrito, ser capaz de compreender e dominar novas situações de trabalho, ser responsável e reconhecido por isso.

A experiência facilita esse processo, pois propicia a regulação dos efeitos das más condições do trabalho e a antecipação dos eventuais incidentes que podem estar relacionados aos recursos humanos, materiais, ambientais.

As competências são as pistas que o psicólogo tem para avaliar as cargas de trabalho e as condições pelas quais as cargas passam a existir, pois elas vão demonstrar a capacidade do trabalhador para agir e, paradoxalmente, são as mesmas competências que vão avaliar, antever e controlar as conseqüências de suas ações. Subjacentes às competências, têm-se normalmente o conhecimento, as habilidades e a experiência do trabalhador. Assim, o seu desenvolvimento propicia uma maior condição de flexibilidade e de adaptabilidade e permite a transferência de aprendizagem. 
Cabe então ao psicólogo descobrir os modos operatórios e os processos cognitivos que o trabalhador desenvolve para lidar com as conseqüencias do próprio trabalho. Ou ainda, nas palavras de Ferreira (2004), conhecer "os saberes tácitos, savoir-faire, regras de metier... para garantir, ao mesmo tempo, o próprio bem-estar, a eficiência e a eficácia na produção de bens e serviços" (p. 182).

\section{Considerações finais}

Os administradores, na organização do processo de trabalho, planejam e fornecem (em tese) os meios necessários à produção, na medida em que dividem as tarefas, elaboram critérios, normas e regras e, em última instância, definem os objetivos a serem alcançados em tal processo. Subjacentes às prescrições e às condições do trabalho encontram-se as exigências externas, ambientais, instrumentais e organizacionais.

As exigências do processo de trabalho são identificadas mediante análise documental e a partir das dificuldades visualizadas e percebidas tanto pelo psicólogo, como pelos trabalhadores. Em relação às conseqüências, elas são expressas em forma de queixas dos gestores ou percebidas através da análise das cargas.

A noção de desempenho humano está diretamente relacionada com a noção de exigência, justamente porque o desempenho é entendido como uma variante da operação de uma determinada necessidade, ou melhor, é a expressão da maneira como o trabalhador responde à necessidade formulada para a realização da tarefa. Sua análise depende inevitavelmente do conhecimento prévio das exigências postas na situação de trabalho.

Os desequilíbrios gerados na relação entre exigências da tarefa e suas conseqüências e pela percepção dos impactos das pressões do meio e dos diferentes graus de sensibilidade humana potencializam o risco inerente ao circuito do trabalho, possibilitando, assim, a expressão de desprazer e de sofrimento do trabalhador. Diante das pressões para atender às exigências referentes ao desempenho e à produtividade, o trabalhador necessita aprimorar suas competências para lidar de forma equilibrada com as discrepâncias geradas entre o que é prescrito e o que efetivamente acontece durante a execução de seu trabalho.

As competências são demonstradas do ponto de vista da atividade, possibilitando assim compreender a ação do trabalhador. Quanto maior a capacidade do trabalhador para adotar um procedimento eficiente em um menor espaço de tempo e com menor custo operacional, mais aprimorada é sua competência e menor sua dificuldade em transitar na diversidade das situações com as quais é constantemente confrontado.

Conhecer os modos de regulação que os trabalhadores utilizam para lidar com as discrepâncias existentes entre o que lhes é prescrito e o que eles realmente fazem é uma das possibilidades que o psicólogo tem de obter pistas para elaborar suas estratégias de intervenção. Tal conhecimento engloba também a identificação das principais variáveis presentes nas exigências da tarefa, nas conseqüências da atividade, nos riscos e nas cargas de trabalho, na variabilidade humana, nas condições em que o trabalho é executado.

O psicólogo do trabalho, ao assentar sua atuação no modelo clínico curativo, incorre no equívoco de iniciar sua investigação pautada apenas nas conseqüências da atividade, bem como de centrar suas intervenções em lógicas reducionistas, que contribuem para resultados pouco eficientes ou, ainda, com efeitos contra-producentes pelo desconhecimento das repercussões de suas ações. Descobrir a forma, o grau, a freqüência e a intensidade de relacionamento dessas principais variáveis críticas é o principal desafio do psicólogo, pois ao elaborar seu plano de ação, tendo como subsídios essas informações, aumentam suas chances 
de atuar de maneira mais consistente e com melhores resultados para o sistema produtivo e para os trabalhadores.

\section{Referências}

Assunção, A. A. (2003). Uma contribuição ao debate sobre as relações saúde e trabalho. Ciência $\mathfrak{E}$ Saúde Coletiva, 8 (4), 56-66.

Cruz, R. M. (2005). Psicologia do trabalho. Apostila da disciplina Psicologia do trabalho, Departamento de Engenharia da Produção, Universidade Federal de Santa Catarina, Florianópolis.

Cruz, R. M. (2004). Distúrbios musculoesqueléticos, processos de trabalho e cultura organizacional. In A. Tamayo (Org.), Cultura e saúde nas organizações (pp. 231-252). Porto Alegre: Artmed.

Cruz, R. M. (2002). O processo de conhecer em avaliação psicológica. In R. M. Cruz, J. C. Alchieri \& J. J. Sarda Junior (Orgs.), Avaliação e medidas psicológicas: produção do conhecimento e da intervenção profissional (pp. 15-24). São Paulo: Casa do Psicólogo.

Dejours, C. (1994). A loucura do trabalho: um estudo de psicopatologia do trabalho. São Paulo: CortezOboré.

Ferreira, M. C. (2004). Bem-estar: equilíbrio entre a cultura do trabalho prescrito e a cultura do trabalho real. In A. Tamayo (Org.), Cultura e saúde nas organizações. (pp. 181-207). Porto Alegre: Artmed.

Ferreira, M. C. \& Freire, O. N. (2001). Carga de trabalho e rotatividade na função de frentista. Revista de Administração Contemporânea, 5 (2), 175-200.

Fleury, M. T. L. (2002). As pessoas na organização. São Paulo: Gente.

Gomes, A. S. (1999). Um modelo construtivista para análise da ação com instrumentos: a aprendizagem consecutiva ao uso de artefatos computacionais. Tese de doutorado, Faculdade de Educação, Universidade Federal do Ceará, Ceará.

Guérin, F., Laville, A., Daniellou, F., Duraffourg, J. \& Kerguelen, A. (2001). Compreender o trabalho para transformá-lo: a prática da ergonomia. São Paulo: Edgard Blucher.

Leplat, J. \& Cuny, X. (1977). Introdução à psicologia do trabalho. Lisboa: Fundação Calouste Gulbenkian.

Segurança e medicina do trabalho. Lei no 6.514, de 22 de Dezembro de 1977. (2003). São Paulo: Atlas.

Mendes, A. M. \& Cruz, R. M. (2004). Trabalho e saúde no contexto organizacional: vicissitudes teóricas. In A. Tamayo (Org.), Cultura e saúde nas organizações (pp. 39-55). Porto Alegre: Artmed.

Montmollin, M. (1990). A ergonomia. Lisboa: Instituto Piaget.

Wisner, A. (1994). Inteligência no trabalho: textos selecionados de ergonomia. São Paulo: Fundacentro.

Wisner, A. (1987). Por dentro do trabalho. Ergonomia: método E̊ técnica. São Paulo: Oboré.

\section{Endereço para correspondência}

biabizzy@ig.com.br,rcruz@cfh.ufsc.br 


\section{Cadernos de Psicologia Social do Trabalho}

\section{Pedido de assinatura e de exemplares avulsos}

Para fazer uma assinatura ou solicitar qualquer exemplar avulso, envie-nos a ficha abaixo preenchida e cheque nominal ao Instituto de Psicologia - USP. Por gentileza, escreva ou telefone para saber os valores atuais de cada exemplar ou da assinatura.

Centro de Psicologia Aplicada ao Trabalho

Av. Prof. Mello Moraes, 1721

Bloco D, sala 163

Cidade Universitária, São Paulo/ SP

05508-030

Endereço eletrônico: cpat@usp.br

\begin{tabular}{|l|l|c|c|}
\hline Quantidade & \multicolumn{1}{|c|}{ Pedido } & \multicolumn{1}{|c|}{ Valor $^{*}$} & \multicolumn{1}{|c|}{ Total } \\
\hline & volume 1 & esgotado & esgotado \\
\hline & volume 2 & & \\
\hline & volume 3/4 & & \\
\hline & volume 5 & & \\
\hline & volume 6 & & \\
\hline & $\begin{array}{l}\text { volume 7 } \\
\text { volume 8 }\end{array}$ & & \\
\hline & volume 9, número 1 & Total: R\$ \\
\hline & assinatura por dois anos (quatro exemplares) & & \\
\hline & & & \\
\hline
\end{tabular}

" Por favor, consultem-nos a respeito dos valores antes de fazer seus pedidos.

\begin{tabular}{|c|c|c|}
\hline Nome: & & \\
\hline Endereço: & & \\
\hline & & CEP: \\
\hline Cidade: & & Estado: \\
\hline Telefone: ( ) & E-mail: & \\
\hline Data: / / & Assinatura: & \\
\hline
\end{tabular}

